\title{
The Malthusian Paradox: Declining food prices in the very long run
}

\author{
$\underline{\text { H. Bloch }}^{\mathrm{a}}$ and D. Sapsford ${ }^{\mathrm{b}}$ \\ ${ }^{a}$ Centre for Research in Applied Economics, School of Economics and Finance, Curtin University, Perth \\ Western, Australia, ${ }^{b}$ David Sapsford, Management School, University of Liverpool, Liverpool, England \\ Email: h.bloch@curtin.edu.au
}

\begin{abstract}
More than two centuries ago in his Essay on the Principle of Population, Thomas Malthus famously issued his dire prediction that mankind was doomed to survival at a subsistence level. His concept of population growth expanding to absorb the available food supply has been roundly contradicted by history, thanks in part to a rapidly dropping birth rate in rich countries. However, economics remains the "dismal science" as his underlying idea of natural resource scarcity impinging on the prospects for progress remains as a cornerstone of modern economics.
\end{abstract}

Without Malthus' population growth dynamics, the existence of finite natural resources remains a constraint on growth. In the case of agriculture, the proposition is that more people or richer people increase the demand for food, and given the constraint on arable land, this means that food becomes scarce. In economics, price is taken as the paramount indicator of scarcity. Yet, as we demonstrate with data stretching back to 1650 , real food prices, the price of food items relative to those of other goods, have fallen dramatically. For example, in 2008 the real price of wheat was only $3 \%$ of its 1650 level, while corresponding ratio for the price of sugar was less than $0.05 \%$.

Of course, the decline in food prices has been far from smooth over the centuries since 1650. Just as in recent years, food prices over the longer span are characterised by substantial volatility. We utilize an approach based on the work of Joseph Schumpeter to separate out long cycles in each price series, and then examine the intra-cyclical trends for indications of increasing or decreasing scarcity of food based on the movement in their real prices over the course of successive cycles.

We examine intra-cyclical trends in prices for nine food commodities; bananas, beef, cocoa, coffee, lamb, rice, sugar, tea and wheat; for up to six cycle periods; 1675 to 1731,1731 to 1786,1786 to 1842,1842 to 1897, 1897 to 1953 and 1953 to 2008. Data are available for us to calculate intra-cyclical trends for all six cycles for five commodities: beef, lamb, sugar, tea and wheat. Among these commodities negative trends dominate, especially for tea and sugar. For the other commodities the number of calculated trends is smaller, but again negative trends dominate. Clearly, the dire predictions of the Malthusian model fail to hold for real prices of food commodities.

What is missing in the "dismal science" that explains the failure of the Malthusian prediction? Clearly, technology plays a central role, but the treatment of technology in economic modelling is limited at best. There has not been much progress beyond Schumpeter's suggestion in The Theory of Economic Development that the answer lies in understanding the process of economic development. In particular, he contrasts the analysis of economic development to that of the equilibrium analysis of a stationary state implicit in the analysis of Malthus and other classical economists. Schumpeter argues that endogenous technical change is built into the capitalist organisation of the economy, which allows entrepreneurs to profit through introducing innovations in the form of new production methods, new products, new forms of organization and the opening of new markets. This implies technical change is assured under capitalism, but it is discontinuous and its nature, location and extent are uncertain. The challenge for economics today is to develop models of the economy that can be used to understand more fully the process of technical change and thereby avoid the false implications of the treatment of natural resource constraints latent in the Malthusian model.

Keywords: Malthus, food prices, Schumpeter 


\section{INTRODUCTION}

More than two centuries ago in his Essay on the Principle of Population, Thomas Malthus (1999 [1798]) famously issued his dire prediction that mankind was doomed to survival at no more than a subsistence level. His concept of population growth expanding to absorb the available food supply has been roundly contradicted by history, thanks in part to a dropping birth rate in rich countries. However, even without Malthus' population growth dynamics, the general approach to the modelling of natural resources in economics means that there is always a constraint on growth such that economics remains the "dismal science".

In the case of food, the proposition is that more people or richer people increase the demand for food, and given the constraint on arable land, this means that food becomes increasingly scarce. In economics, price is taken as the paramount indicator of scarcity. Yet, as we demonstrate with data stretching back to 1650 , real food prices, the price of food items relative to those of other goods, have generally fallen, often dramatically. For example, in 2008 the real price of wheat was only $4 \%$ of its 1650 level, while corresponding ratio for the price of sugar was less than $0.05 \%$.

The apparent paradox of a larger, better fed population and lower food prices is explained by recourse to technical change. Clearly, yields per hectare have increased dramatically over the centuries as new production techniques, new crop varieties and new methods of organising production have been introduced. The problem for economic modelling is that both the classical analysis of Malthus' time and more recent neoclassical analysis assume fixed technology and focus on the allocation of limited supplies of inputs to production among competing uses. The dynamics of the supply of inputs to production is dealt with separately, such as with Malthus' now abandoned principle of population.

Schumpeter (1934) criticises this treatment as an obstacle to understanding the development of the economy and society over time. Schumpeter argues that technical change comes from within the economic system, especially under capitalism where profits represent the return to successful innovation. Profitable innovation directly or indirectly increases the productivity of inputs to production in terms of their contribution to output as measured by its value to final consumers. In this way, innovation releases the constraints posed by limited quantities of inputs to production. Importantly, this process applies to all inputs to production, whether they are gifts of nature (such as land), human effort or produced means of production (capital).

The decline in food prices has been far from smooth over the last three and a half centuries. Just as in recent years, food prices over the longer span are characterised by substantial volatility. One influence on price fluctuations that is emphasized in Schumpeter (1939) is the business cycle. We adapt Schumpeter's approach to separate out long cycles in the prices of nine food products: bananas, beef, cocoa, coffee, lamb, rice, sugar, tea and wheat; for up to six cycle periods; 1675 to 1731,1731 to 1786,1786 to 1842,1842 to 1897,1897 to 1953 and 1953 to 2008 .

Negative trends dominate among the intra-cyclical movements, but there are differences across commodities that suggest the operation of supply and demand factors specific to each commodity. Particularly notable is that beef, cocoa and lamb actually experience a net increase in real price over the full period for which data are available. At the other extreme, the net price declines for sugar and tea are particularly severe.

The remainder of the paper is organised as follows. First, we examine the Malthusian model and its neoclassical successor to identify differences between the dynamic modelling of natural resources and that accorded to other inputs to production. Next, we contrast this treatment to the dynamics in Schumpeter's analysis of the endogenous technical change. This is followed by an examination of the data on intra-cyclical price trends for the nine agricultural commodities, leading to a summary of the findings in the conclusion.

\section{CLASSICAL AND NEOCLASSICAL MODELLING}

Classical economists, including Malthus, sought to explain how a self-regulating, market-based economy with private property could generate growth and prosperity. Smith (1910 [1776]) emphasised the role of the invisible hand in ensuring that production guided by self interest would nonetheless satisfy the needs and desires of the ultimate consumers. Ricardo (1911 [1821]) worked out the implications this process for the distribution of income of expansion of the economy in terms of employing more labour and capital on fixed amounts of land, while Malthus (1999 [1798]) developed his principle of population and its implications for the standard of living. 
Classical analysis implicitly treats the supply of land as given. Expansion of production occurs through increasing the use of either produced means of production or labour, which in either case increases the relative scarcity of land and increases its price. With technology also implicitly assumed to be unchanged, products that require relatively more land in their production rise in price relative to other products. Hence, prices of food products are expected to rise relative to prices of manufactures. ${ }^{1}$

Neoclassical economics formalises the input-output relation in terms of a production function,

$$
\mathrm{X}=\mathrm{f}(\mathrm{L}, \mathrm{K}, \mathrm{N})
$$

where $\mathrm{X}$ is the amount of output produced, $\mathrm{K}$ is the amount of capital (man-made means of production) used in production, $\mathrm{L}$ is the amount of labour used and $\mathrm{N}$ the amount of land (or natural resources more generally). Here, as with classical analysis, the assumptions of fixed technology and non-negative marginal productivity of inputs (the derivative of output with respect to each input is not negative) imply that output increases only as inputs increase.

In neoclassical analysis high prices of inputs are related to high productivity at the margin. Increasing marginal productivity of a fixed quantity of land results when there is capital growth with saving (the diversion of some production into expanding the means of production) or labour growth with population expansion (Malthus' principle of population being an extreme version of the general expectation that rising living standards reduce death rates and thereby expand the population). The rising marginal productivity of land then implies a rising land value and rising real prices for products that are relatively intensive in their use of land.

\section{SCHUMPETER AND ENDOGENOUS TECHNICAL CHANGE}

Schumpeter (1934) ascribes economic growth to a discontinuous process of innovation rather than to the steady growth of inputs of capital and labour as in classical and neoclassical analysis. In particular, he identifies economic development with the introduction of new methods of production, new products, new markets, new sources of supply and new forms of organisation. In terms of (1), the difference is between a fixed function where input growth drives output growth and a function that changes over time in such a way that the same amounts of input lead to greater output, so that there is technology driven growth rather than input driven growth.

This difference in the drivers of growth is essential from the perspective of understanding the likely impact of economic growth on food prices. While growth in classical or neoclassical analysis drives up the real price of land-intensive products, there is no such presumption in Schumpeter's analysis. Instead, movements in real prices depend on the locus of innovation, with innovations that raise productivity of any input contributing to declines in real prices.

Much discussion of the role innovation in economic development emphasises the Industrial Revolution and the subsequent rapid expansion of manufacturing. However, Schumpeter (1939) points to numerous examples of innovation in agriculture, mining and handicraft production going back to well before the Industrial Revolution. Agricultural production has continued to grow with use of the products of the Industrial Revolution, especially machinery and chemicals, but also through innovations in the organisation of production, introduction of new plant varieties and expansion in areas of cultivation. Whether innovation in food production is sufficient to offset the effect of other developments in the economy, including growth due to expansion of capital and labour inputs, depends on specific historical developments and could differ across particular products.

Before examining the historical data to see what has actually happened to real prices of food products over the past three and a half centuries, we consider the cyclical nature of price movements in Schumpeter's analysis. Cycles in price movements are an expected consequence of innovation leading to structural change and uneven development. The price level rises during the upswing of a cycle and falls during the downswing.

\footnotetext{
${ }^{1}$ A major focus in classical analysis is on the contribution of international trade to a high standard of living. Trade helps raise living standards by lowering the domestic price of products whose production uses relatively large amounts of inputs that are scarce at home relative to their availability abroad. With growth in Britain pushing food prices up during the early $19^{\text {th }}$ Century, David Ricardo argued for repeal of the Corn Laws, which restricted imports of wheat into Britain, because this would improve the living standard of the working class.
} 
These cyclical swings in prices obscure the working of innovation on the trend in particular goods or groups of goods. This is particularly true for primary commodities, which dominate listings of goods with "sensitive prices" that Schumpeter $(1939$, p.525) recognizes 'will display cycles in prices both relatively promptly and relatively strongly'. Thus, the movement over time in prices of primary products will reflect the impact of general price cycles as well as any influences of innovation.

Schumpeter argues that the bunching of economic innovations imparts a rhythm to the pattern of economic activity. In particular he emphasizes a long-wave or Kondratieff cycle of some 55 to 56 years. He identifies two such cycles in Schumpeter (1939): 1787 to 1842 and 1842 to 1897. The first cycle is associated with the Industrial Revolution, while the latter is connected to the expansion of railroads through Europe and North America.

Studies by Mensch (1979), Tylecote (1991) and Freeman and Louçã (2001) stay close to Schumpeter's historical and conceptual emphasis on the role of innovations. However, these studies discard Schumpeter's characterization of regular cycles in favour of a pattern with irregular amplitude and duration. The terminology of a long wave is used in place of the Kondratieff cycle, with the long wave having the duration of something like a half century, but with no clear agreement on the dating of particular cycles.

Much of the empirical work on business cycles has followed Kuznet's (1930) seminal contribution that focuses on shorter cycles and emphasises movements in quantities along with movements in prices. ${ }^{2}$ Kuznet's approach has been further developed by the National Bureau of Economic Research (NBER), leading to a procedure for the dating of cycles that is based exclusively on movements in quantities rather than prices. This approach is not very useful for our purposes due to its emphasis on quantities rather than prices and because of the focus on shorter business cycles.

Another alternative approach to modelling of cycles is to formalise the adjustment process for economic variables in terms of a series of difference equations in the time domain as, for example, in Hicks (1956) or Allen (1968). The basic framework of the models is the multiplier - accelerator interaction, with or without floors and ceilings to prevent explosive dynamics. Here, the periodicity of the cycles depends on the lags in the adjustment of variables, as well as the direction and magnitude of the parameters in the difference equations. No consensus has developed on the appropriate values of these lags and parameters or even on the appropriate methodology for estimation. Thus, there is no clear guidance given on the dating of cycles in this approach.

We find merit in Schumpeter's argument that innovation leads to long cycles in prices. Further, we accept that these cycles might have particularly strong impact on primary commodities, including food. In the absence of a clear alternative for dating the cycles, we adopt Schumpeter's original dating of the cycles from 1787 to 1842 and 1842 to 1897 . We then extend his method to add two more recent cycles: 1897 to 1953 and 1953 to 2008, and two earlier cycles: 1731 to 1787 and 1675 to 1731 .

\section{FOOD PRICES IN THE LONG RUN}

We examine long historical series of price indexes for food products. The price indexes are each deflated by a corresponding price index for manufactured goods to provide a real price index for each food product. The series have been constructed as part of a database on the prices of internationally traded primary commodities starting from 1650. These data come from a variety of sources, which are described in the Appendix to Harvey, et al (2010). Data are available for us to calculate intra-cyclical trends for all six cycles for five commodities: beef, lamb, sugar, tea and wheat, while for other commodities the number of calculated trends is smaller.

The patterns of price movement for wheat, sugar, beef and lamb, the four price series that go all the way back to 1650 , are depicted in Figure 1. The vertical axis in each figure gives the natural logarithm of the real price index with a base value of 1.0 in the starting year of 1650. The logarithmic scale is used so that a given vertical distance on the graph represents the same percentage change regardless of the initial value. For example, a rise of 0.1 represents a ten percent increase whether the rise starts from an index value of $0.5,1.0$ or $2.0^{3}$

\footnotetext{
${ }^{2}$ Kuznets (1940) provides a sharp critique of Schumpeter's embrace of regular cycles and his arguments for long cycles based on innovation.

${ }^{3}$ Because of the peculiarities of percentage calculations, a decrease of .1 represents a percentage decrease of $100 / 1.1$ or 9.09 percent. However, the amount of the percentage decrease is the same from any starting value.
} 


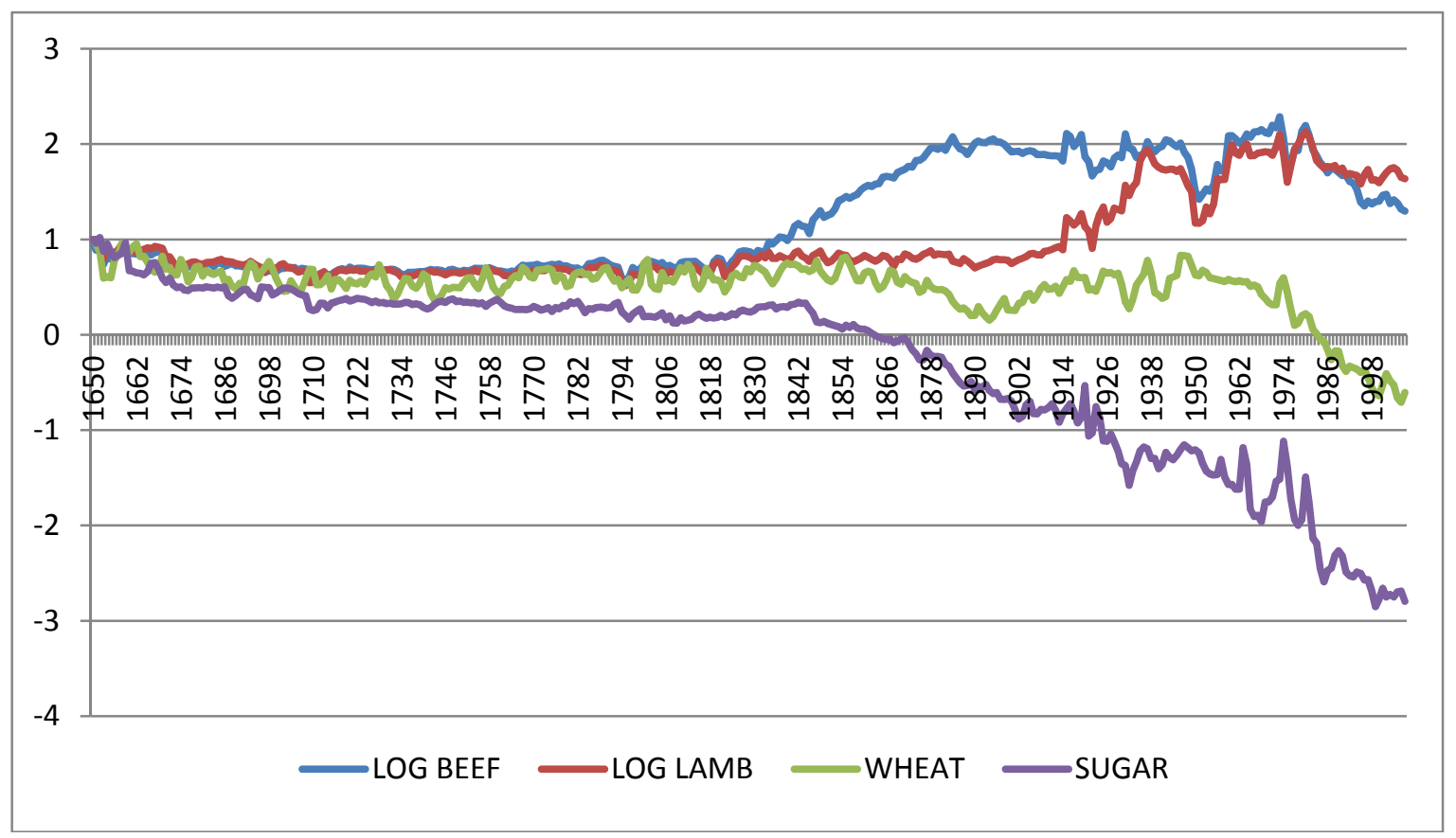

Figure 1 - Real Prices of Beef, Lamb, Sugar and Wheat 1650 - 2008

All four series in Figure 1 move downward through the middle of the Eighteenth Century, after which sugar prices continue to decline while the other series level off. Beef prices rise substantially during the Nineteenth Century, while lamb prices follow after the middle of the Twentieth Century. In contrast, both wheat and sugar prices fall dramatically after this time. Finally, all prices decline substantially in after about 1980. Notably, all series have considerable fluctuations, especially from the start of the Twentieth Century.

To remove the cycles associated with the Kondratieff cycles identified using Schumpeter's dating method, we calculate intra-cyclical trends for each food product in terms of the average annual rate of change of price for each of the six cycles: 1675-1731, 1731-1787, 1787-1842, 1842-1897, 1897-1953 and 1953-2008. These intra-cyclical trends are shown in Table 1 along with the average annual rates of change over the full period for which data are available for that particular series.

Table 1 - Intra-cyclical Trends in Food Prices (average \% per annum)

\begin{tabular}{|llllllllll|}
\hline Period & Banana & Beef & Cocoa & Coffee & Lamb & Rice & Sugar & Tea & Wheat \\
$1675-1731$ & & -0.045 & & & -0.075 & & 0.590 & 1.190 & -0.438 \\
$1731-1787$ & & 0.129 & & -0.144 & 0.049 & -0.395 & -0.081 & -0.685 & 0.222 \\
$1787-1842$ & & 0.742 & & -0.531 & 0.309 & -0.282 & 0.102 & -0.207 & 0.237 \\
$1842-1897$ & & 1.550 & 1.362 & 0.128 & -0.167 & 0.731 & -1.852 & -1.313 & -0.731 \\
$1897-1953$ & & -0.875 & 0.127 & -0.212 & 0.993 & -1.928 & -1.346 & -0.834 & 0.596 \\
$1953-2008$ & -0.839 & -0.267 & -1.014 & -2.960 & 0.611 & -0.769 & -2.415 & -3.526 & -1.995 \\
Full period & -0.819 & 0.107 & 0.129 & -0.704 & 0.189 & -0.362 & -1.050 & -1.182 & -0.403 \\
\hline
\end{tabular}

A positive price trend in Table 1 indicates increasing scarcity, while a negative trend indicates decreasing scarcity. There is clearly a mix of positive and negative trends over both time and products. Negative intra- 
cyclical trends clearly dominate for some food products, such as tea (5 out of 6 cycles), sugar (4 out of 6 cycles), coffee ( 4 out of 5 cycles) and rice ( 4 out of 5 cycles), while positive trends dominate for lamb (4 out of 6 cycles). Comparing across cycles, eight of the nine food products (all but lamb) experience pronounced negative trends for the most recent cycle, 1953 to 2008, with rates of decrease in real price of more than one percent a year for five commodities (cocoa, coffee, sugar, tea and wheat). In contrast, during the cycle from 1787 to 1842 , the cycle Schumpeter associates with the Industrial Revolution, there are more products with price increases than prices decreases. This mixed pattern suggests a variety of influences at work, but clearly the data fail to support the dire predictions of the Malthusian model for an increasing real price of food.

It is interesting to reflect on the characteristics of those food products that have defied the predominant trend towards falling real prices, namely beef, lamb and cocoa. These are all considered to be luxury foods, with demand that rises relative to other food products with the rising standard of living over the centuries. Even if productivity improvements for these products were equivalent to those affecting other food products, rising relative demand would lead to rising relative price. Thus, relative demand seems to play an important role in explaining the differences in price trends for different food products over time.

In terms of the comparing price trends over different cycles, the dominance of upward price trends during the cycle from 1787 to 1842 seems to reflect sharp increases in manufacturing productivity during the height of the Industrial Revolution. Declines in prices of manufactures following these productivity improvements raise the real price of food products as the manufacturing price index is used to deflate the price of each food product in calculating the real price. Demand influences also seem important in the variation of price trends over cycles. Relatively slow growth in the developed economies over the period since 1980 has contributed to the predominance of negative price trends in the cycles from 1953 to 2008. Even the rapid growth of China and other developing economies towards the end of this cycle has not been sufficient to offset the trend.

\section{CONCLUSIONS}

Contrary to the dire predictions made by Malthus in his Essay on the Principle of Population, the world has not been kept to a subsistence level existence, at least for substantial proportions of the population. Rather than experience increasing scarcity of food as reflected in rising real prices of food products, the dominant trend has been to declining real prices. Of the nine food products examined, six have had net decreases in their real prices over a period of time stretching back in some cases to 1650 . The magnitude of the price decreases for these products is in each case larger than the magnitude of the price increases for the other three products. The dominance of price declines is clear in each of the six long business cycles over three and a half centuries, aside from equal prices increases and decreases at the height of the Industrial Revolution from 1787 to 1842 . The most recent cycle, 1953 to 2008 has seen price decreases for eight of the nine food products.

What is missing in the "dismal science" that explains the failure of the Malthusian prediction? Clearly, technology plays a central role. We note that innovations in production, new methods of organisation and new sources of supply have generally been sufficient to offset the tendency towards higher prices as expanded industrial production and population increases the demand for food. Yet, the treatment of innovation and technological change in economic modelling is limited at best. The challenge for economics today is to develop models of the economy that can be used to understand more fully the process of technical change and thereby avoid the false implications of the treatment of natural resource constraints latent in the Malthusian model.

\section{ACKNOWLEDGMENTS}

Our thanks go to Jakob Madsen for constructing the data series used in this paper and providing these data to the authors.

\section{REFERENCES}

Allen, R.G. D. (1968), Macro-economic Theory: A Mathematical Treatment, London, Macmillan.

Freeman, Chris and Louçã, Francisco (2001), As Time Goes By, Oxford, Oxford University Press. 
Bloch and Sapsford, The Malthusian Paradox: Declining food prices in the very long run

Harvey, David I., Kellard, Neil M., Madsen, Jakob B. and Wohar, Mark E. (2010), 'The Prebisch-Singer hypothesis: Four centuries of evidence', Review of Economics and Statistics, 92, 367-377.

Hicks, John R. (1956), A Contribution to the Theory of the Trade Cycle, Oxford, Clarendon Press.

Kuznets, Simon S. (1930), Secular Movements in Production and Prices, Boston, Houghton Mifflin.

Kuznets, Simon S. (1940), 'Schumpeter's Business Cycles', American Economic Review, 30, 257-71.

Malthus, Thomas (1991 [1798]), An Essay on the Principle of Population, Oxford, Oxford University Press.

Mensch, Gerhard (1979), Stalemate in Technology, Cambridge, MA, Ballinger.

Ricardo, David (1911), The Principles of Political Economy, London, J. M. Dent Everyman's Library.

Schumpeter, Joseph A. (1934), The Theory of Economic Development (translation of second German edition by Redvers Opie), London, Oxford University Press.

Schumpeter, Joseph A. (1939), Business Cycles, Volumes 1 and 2, New York, McGraw-Hill.

Smith, Adam, (1910 [1776]), The Wealth of Nations, J. M. Dent Everyman's Library.

Tylecote, Adnrew (1992), The Long Wave in the World Economy, London, Routledge. 